American Journal of Pharmaceutical Education 2018; 82 (9) Article 6444.

\title{
RESEARCH
}

\section{Comparison of Student and Patient Perceptions for Medication Non-adherence}

\author{
Patricia L. Darbishire, PharmD, ${ }^{\mathrm{a}, \mathrm{c}}$ Daraoun Mashrah, PharmD ${ }^{\mathrm{b}}$ \\ a Purdue University College of Pharmacy, West Lafayette, Indiana \\ ${ }^{\mathrm{b}}$ University of Michigan Hospital, Ann Arbor, Michigan \\ ${ }^{c}$ Editorial Board Member, American Journal of Pharmaceutical Education, Arlington, Virginia \\ Submitted April 4, 2017; accepted October 10, 2017; published November 2018.
}

Objective. To compare pharmacy students' perceptions with patients' reasons for medication nonadherence.

Methods. Pharmacy students completing an experiential rotation recruited patients exhibiting medication non-adherence from community pharmacies and asked them to respond to statements about reasons for their medication non-adherence. Patient responses were ranked in order of prevalence and compared to self-reported student perceptions on reasons for non-adherence.

Results. There was a significant difference between patients' and students' rankings of reasons for medication non-adherence. Significant factors for patients included medications that interfere with lifestyle, sexual health and drinking alcohol; whereas, students believed that cognitive-related issues were patients' primary reasons for non-adherence to their medications.

Conclusion. Educational opportunities to reflect on and discuss differing perspectives should be provided in the pharmacy curriculum to better equip students to address medication adherence issues and improve patient care.

Keywords: medication adherence, medication compliance, medication persistence, pharmacy education

\section{INTRODUCTION}

Medication adherence is defined as the extent to which a patient acts in accordance with a prescribed medication regimen. ${ }^{1-3}$ Medication non-adherence occurs when a patient intentionally or unintentionally does not follow prescribed medication regimens. ${ }^{4}$ Studies concur that about $50 \%$ of patients never obtain, obtain but do not use, start and stop prescribed medications, or take them inappropriately. ${ }^{4-9}$ The problem is most striking in patients with chronic conditions; some reports say that the non-adherence rate is close to $70 \%{ }^{1,3,7,10-12}$ Medication non-adherence contributes to increased health care utilization and costs, poor health outcomes, decreased quality of life, and worsening of disease or death. ${ }^{1,13-16}$

A systematic literature search was performed in Medline, PubMed, CINAHL, Cochrane, International Pharmaceutical Abstracts and Google Scholar for the years 2000 to 2016 to identify published literature on student education related to medication adherence. The review revealed that medication adherence concepts are commonly taught in didactic pharmacy curricula, but

Corresponding Author: Patricia L. Darbishire, Purdue University College of Pharmacy, West Lafayette, Indiana. Tel: 765-495-1380. E-mail: darbishi@purdue.edu there is minimal evidence that schools provide activelearning opportunities whereby students experience the actual difficulties of adhering to prescribed therapy and then reflect on the experience. ${ }^{17}$ Some schools incorporate role-play simulations where students take placebo medications to experience the difficulty of adhering to therapy and to enhance empathy toward patients taking multiple medications. ${ }^{18-20}$ Volino described activities where students were placed into randomized groups to demonstrate improved adherence following counseling interventions. ${ }^{21}$ The authors of this study did not find any article describing educational activities whereby students explore their perceptions on reasons for nonadherence and contrast them with the views of patients. The objective of this research was to explore differences between student perceptions and those of the patients they serve, to determine how much emphasis this topic should have in pharmacy education. The authors hypothesized that significant differences exist between groups, and believe exposure of this discordance will provide a new avenue for medication adherence education. A model of a proposed mechanism to improve patient health outcomes through inclusion of this research in education and training is provided in Table 1. 


\section{American Journal of Pharmaceutical Education 2018; 82 (9) Article 6444.}

Table 1. 7-Step Model for Improving Medication Adherence

Step 1. Examine existing research on factors that lead to medication non-adherence.

Are health care student perspectives on reasons for medication non-adherence different from those of the patients they serve?

Step 2. Discuss findings in health care education.

Does the curriculum include content on how differing perspectives can affect provision of patient care?

Step 3. Engage students in simulations and reflection for deeper understanding.

Does the curriculum employ teaching pedagogies that promote deep understanding, empathy, and enhance students' motivation to assist patients in adhering to therapy?

Step 4. Enhance students' professional competence.

Does the experiential learning program solidify professional competence through opportunities to communicate with patients about factors affecting adherence?

Step 5. Build trust and mutual alliance with patients.

Does the curriculum include opportunities for students to establish a trusting relationship with a patient?

Step 6. Identify reasons for non-adherence and provide tools for improvement.

Does the curriculum include opportunities for students to elucidate reason(s) for a patient's non-adherence and suggest methods/tools for improvement?

Step 7. Meet patient health care goals.

Does the curriculum provide opportunities to teach students how to measure success, eg, reduction of health care utilization, costs, medication side effects, disease, and/or enhanced quality of life?

\section{METHODS}

During their first year of the professional pharmacy program at Purdue University College of Pharmacy, student interns work with patients in a campus-based community pharmacy and learn medication adherence concepts in the Introductory Pharmacy Practice Experience (IPPE) program. These activities provide a foundation for more advanced medication adherence assignments taken during the second year of the IPPE program.

To develop the second year assignments, the instructor first reviewed several validated medication adherence scales. These included the Brief Medication Questionnaire, the Medication Adherence Questionnaire, Medication Adherence Rating Scale, Self-efficacy for Appropriate Medication Use Scale, ASK-20, and the Hill-Bone Compliance Scale. ${ }^{22-27}$ Some scales measured general non-adherence and some were developed for use in specific disease states. From these scales, the instructor developed a list of 16 factors commonly believed to contribute toward medication non-adherence. These factors were used to prepare statements to which a patient could respond with their level of agreement. The list of factors was not intended to be all-inclusive, but to represent the most common reasons for medication non-adherence found in health care literature. The statements were reviewed by two community pharmacy preceptors, two students on the Purdue Experiential Learning Advisory Council, and faculty member who had previously published on the topic of medication adherence. Their feedback was incorporated into the final statements. The statements were used in two IPPE medication adherence assignments - a patient interview and a self-reflective student assignment. Both patient and student data were extracted from these assignments for comparative purposes.

Second professional year (P2) IPPE students were provided with a workbook of assignments to complete at their own pace over a 4-week community pharmacy rotation. For the patient interview assignment, students recruited and interviewed a patient exhibiting medication non-adherence in order to identify factors that contributed to their non-adherence. Medication non-adherence was determined through analysis of multiple medication profiles at the student's assigned community pharmacy practice site. Students were instructed to identify a patient who refilled at least one medication excessively early or late (subjective) at least half of the time in the past 6 months of use. Additional criteria for patient inclusion were age $\geq 18$, ability to understand and speak English, never previously interviewed by a student about their medications, taking at least three prescribed chronic-use medications and exhibiting medication non-adherence with at least one or more of these medications. Preceptors assisted students in the final determination of a candidate for the assignment. Students contacted patients by telephone or in person at the pharmacy to request a live interview. Seven out of 310 students reported the need to contact more than one patient for an interview. The patient interviews were conducted at a location convenient to both the patient and the student, which was most often the pharmacy or a coffee shop. As part of the interview, students asked their patients to indicate their level of agreement $(1=$ strongly disagree, $5=$ strongly agree $)$ with the 


\section{American Journal of Pharmaceutical Education 2018; 82 (9) Article 6444.}

16 statements about medication non-adherence. Two years of students (2010-2012) recorded their patients' responses into an electronic course management system, devoid of any patient identifiers.

In 2013, the instructor removed the patient rankings portion of the interview assignment to decrease the length of the interview and allow students time to apply motivational interviewing techniques learned in class. Instead, as part of a self-reflection assignment, P2 students were asked to rank the same 16 reasons for non-adherence in order of significance, based on general perceptions from working with patients in a community pharmacy. A ranking of 1 indicated what they believed to be the most important reason for medication non-adherence among patients, and a ranking of 16 indicated the least significant factor in medication non-adherence (Table 2).

Following receipt of an exemption from the Purdue University Institutional Review Board, inferential and descriptive statistics were performed on the data from both assignments using Microsoft Excel Version 2013 (Redmond, WA). The researchers first analyzed the two years of data from the patient interview assignment (20102011, $\mathrm{n}=152$ and 2011-2012, $\mathrm{n}=158)$. A mean and standard deviation were calculated from the patients' ratings for each of the 16 statements, which were then ordered from highest mean score to lowest mean score in order to provide a ranked list. The results for each year of data were analyzed separately, and in aggregate.

The student self-reflection assignment resulted in an additional two years of student data (2013-2014, $\mathrm{n}=136$ and 2014-2015, $\mathrm{n}=150$ ). A mean ranking was determined for each factor for each year and in aggregate. The factors were ordered from smallest mean score (highest ranking) to largest mean score (lowest ranking) to determine the overall student ranking of the factors and allow for comparison with the 2010-2012 patient interview data (Table 3).

The authors used a dependent $t$-test, which compares the means of two related groups (students and patients were related by each factor) to detect statistical differences at a significance level of $p<.05$ between the group means. This allows for comparison of the average patient ranking to the average student ranking. The dependent t-tests were based on "difference scores." Specifically, if the same reason was provided at the same rank order by patients and students, it was equivalent to a gain score of zero. If the factor was ranked differently, the difference score was equivalent to the number of ranks they were apart. The differences were summed and divided by 16 (the number of factors) which resulted in an average difference score. This number was divided by the SD of the difference scores to calculate the t-statistic and corresponding $p$-value with $\mathrm{df}=15$ to determine if there was a true difference between patient rankings and student rankings.

Next, the 16 factors were grouped into three general categories for further analysis, including those affecting lifestyle, understanding/cognitive-related factors and logistical/physical issues (Table 4).

Lastly, the authors performed correlations at a significance level of .05 , between the two years of patient data and the two years of student data to determine the consistency of rankings between years. Figure 1 shows a comparison of mean rankings for the two patient groups and Figure 2 shows the mean rankings of the two student groups.

\section{RESULTS}

Second professional year IPPE students completed 310 patient interviews on medication non-adherence over the years 2010-2011 $(\mathrm{n}=152)$ and 2011-2012 $(\mathrm{n}=158)$, as well as 286 self-reflections over the years 2013-2014 $(n=136)$ and 2014-2015 $(n=150)$. All students completed the assignment for their respective P2 IPPE curricula.

Table 3 shows the comparison of patient and student rankings from the two assignments. The researchers found a significant difference between patients' and students' rankings of medication non-adherence factors $(4.38,3.42), t(15)=5.11, p<.001, \mathrm{~d}=1.27$. There was a very strong correlation between the two patient groups' rankings between the two years $(r=.99)$. Likewise, there was a very high correlation between the two years of students' rankings, with both student groups ranking the top $6 / 16$ factors in the same order $(r=.99)$.

Table 2. Second Professional Year IPPE Assignment Descriptions

\begin{tabular}{ll}
\hline Patient Interview Responses & \multicolumn{1}{c}{ Self-Reflective Student Perceptions } \\
\hline $\begin{array}{l}\text { Data collected from } 2010 \text { to } 2012 \\
\text { Students interviewed a patient exhibiting non-adherence and } \\
\text { recorded the patient's level of agreement with 16 }\end{array}$ & $\begin{array}{l}\text { Data collected from 2013 to 2015 } \\
\text { Students ranked 16 statements based on their general } \\
\text { statements regarding factors that lead to medication }\end{array}$ \\
$\begin{array}{l}\text { non-adherence, using a scale of } 1=\text { strongly disagree } \\
\text { to 5 }=\text { strongly agree. }\end{array}$ & $\begin{array}{l}\text { prescribed therapy, with } 1=\text { the most common reason that } \\
\text { patients do not adhere to therapy and 16=the least common } \\
\text { reason. }\end{array}$ \\
\hline
\end{tabular}




\section{American Journal of Pharmaceutical Education 2018; 82 (9) Article 6444.}

Table 3. Medication Non-Adherence Factors in Ranked Order of Significance for Patients and Students

\begin{tabular}{|c|c|c|}
\hline Ranking $^{a}$ & $\begin{array}{l}\text { Patients' Reasons } \\
\qquad(\mathbf{N}=\mathbf{3 1 0})\end{array}$ & $\begin{array}{c}\text { Students' } \\
\text { Perspectives } \\
(\mathrm{N}=\mathbf{2 8 6})\end{array}$ \\
\hline 1 & Too many & Forget \\
\hline 2 & Too expensive & Too expensive \\
\hline 3 & Forget & Too many \\
\hline 4 & Drink alcohol & Schedule compslex \\
\hline 5 & Interferes with lifestyle & $\begin{array}{l}\text { Don't understand } \\
\text { importance }\end{array}$ \\
\hline 6 & Difficult to swallow & Dosing confusing \\
\hline 7 & $\begin{array}{l}\text { Don't understand } \\
\text { purpose }\end{array}$ & Interferes with lifestyle \\
\hline 8 & Difficult to open & $\begin{array}{l}\text { Don't understand } \\
\text { purpose }\end{array}$ \\
\hline 9 & Schedule complex & Instructions difficult \\
\hline 10 & Interferes with sex & No transport \\
\hline 11 & Dosing confusing & Physical condition \\
\hline 12 & Difficult to read & Difficult to read \\
\hline 13 & Physical condition & Difficult to swallow \\
\hline 14 & No transport & Difficult to open \\
\hline 15 & Instructions difficult & Drink alcohol \\
\hline 16 & $\begin{array}{l}\text { Don't understand } \\
\text { importance }\end{array}$ & Interferes with sex \\
\hline
\end{tabular}

${ }^{a} 1=$ most significant factor and $16=$ least significant factor

Both patients and students were in agreement regarding the top three reasons for non-adherence, although their ranked order differed. These reasons included taking too many medications, cost, and failure to remember. Patients indicated the number one reason for non-adherence is too many medications, whereas students believed that the primary issue was forgetfulness. After the top three factors, there was significant discord between patients' reasons and students' perceptions on reasons for non-adherence.

The data revealed that issues affecting a patient's lifestyle, such as medication costs, sexual health and drinking alcohol were ranked higher in importance for patients, compared to student perceptions that cognitiverelated issues such as confusion, dosing complexity and lack of understanding were often primary problems. Logistical/physical issues such as difficulty reading labels and transportation were ranked in the lower half for both groups (Table 3).

\section{DISCUSSION}

Our literature review on medication adherence revealed studies of various sample sizes, designs, and limitations. Many focused on specific disease states. Study results on the primary factors contributing to medication non-adherence were sometimes contradictory. ${ }^{28}$ This research focused on single contributors commonly discussed in health care literature, but others are described as well. These include, but are not limited to age, health literacy, health beliefs, traditions, social support, the patient's disease state(s), and specific types of medication(s) used. ${ }^{3,29,30,31}$ For example, Mert reported that the adherence rates of

Table 4. Statements Provided to Patients (Containing Factors) by Category

Lifestyle

Taking medications interferes with my lifestyle.

My medications are too expensive.

If I drink alcohol, I don't take my medication dose.

Medications interfere with my sexual health.

I take too many medications.

Understanding/Cognitive-related

I don't understand the importance of my medication.

I forget to take my medication(s).

The instructions on my pill bottles are difficult to understand.

My medication dosing schedule is too complex.

I don't understand the purpose of my medication.

My medication dosing schedule is confusing.

Logistical/Physical Issues

I have difficulty getting to the pharmacy (no transportation).

It is difficult to swallow my pills.

My physical condition makes taking medications difficult.

It is difficult for me to open my pill bottles.

It is difficult for me to read the directions on my pill bottles. 


\section{American Journal of Pharmaceutical Education 2018; 82 (9) Article 6444.}

\subsection{0}

4.00

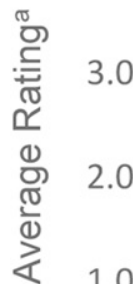

1.00

0.00
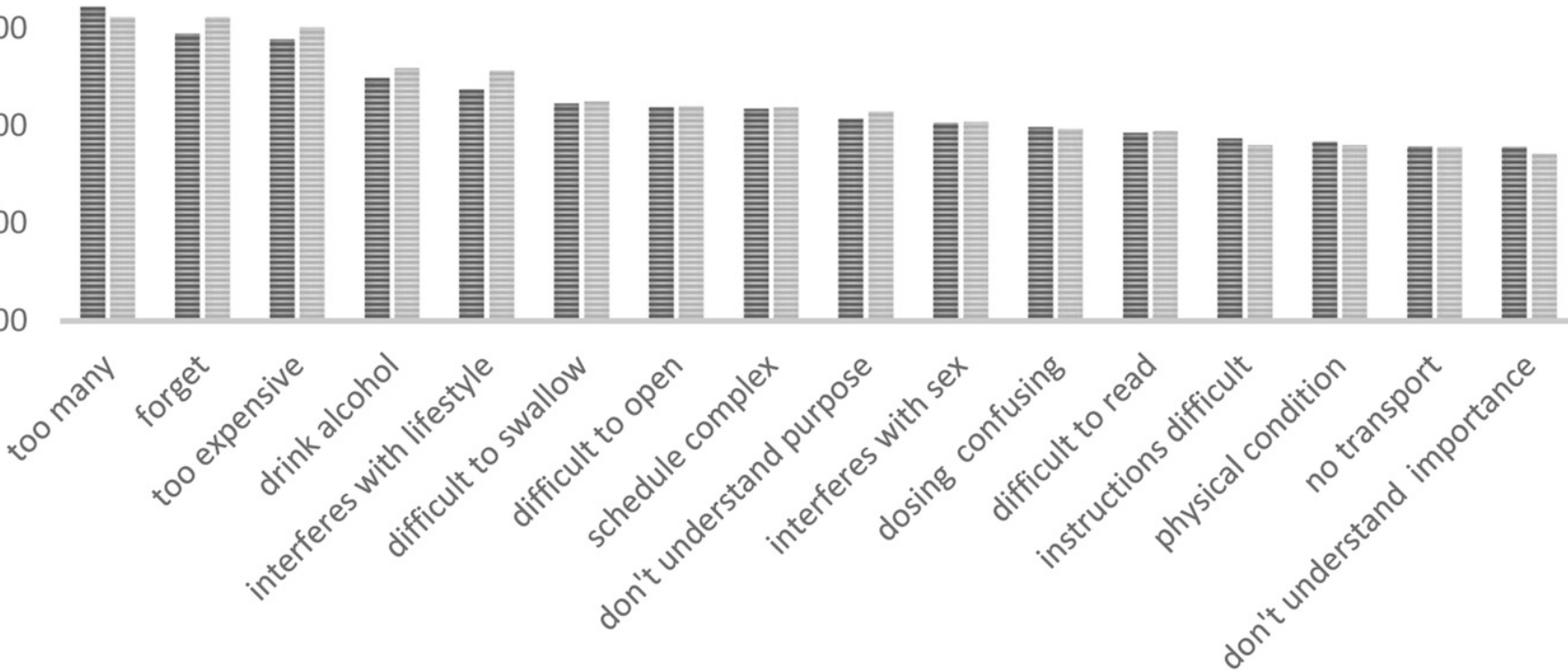

Factors for Medication Non-adherence

Figure 1. Comparison of Average Ratings from Two Patient Groups.

patient populations with psychiatric issues were most influenced by "failure to accept the disease," "cycles of feeling better and thinking there was no longer a need for the medication," and "medication side effects." ${ }^{30}$ Walsh reported that adherence in patients with HIV was most influenced by "not having the medication with them," "feeling

\subsection{0}

14.00

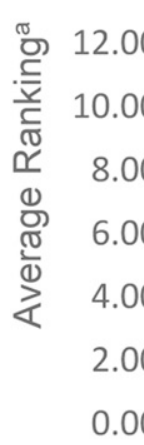

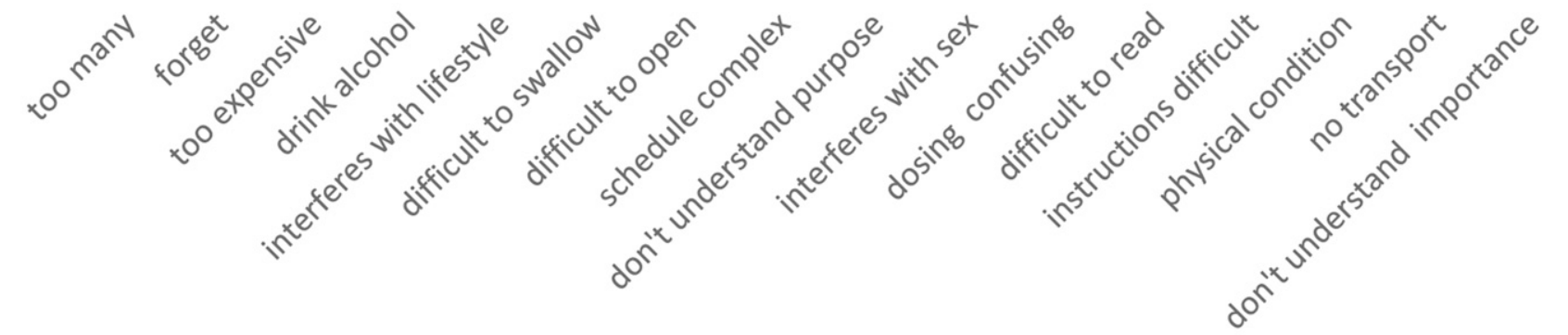

Factors for Medication Non-adherence

Figure 2. Comparison of Average Rankings from Two Student Groups. 


\section{American Journal of Pharmaceutical Education 2018; 82 (9) Article 6444.}

too ill to take the medication," or "forgetting the correct time to take the medication." 31 Svensson and McHorney reported that "general dislike of medications" and "side effects" were primary reasons for non-adherence to hypertension and diabetes medications, while believing their "condition was not life threatening" was more likely to be an issue in patients with osteoporosis. ${ }^{5,9}$ In fact, studies demonstrate that reasons for non-adherence are somewhat predictable based on disease state and therapy. Proactively discussing predictable factors with patients is critical to individualized patient care.

Two related concepts affecting medication adherence include effective health care provider communication, and a genuine relationship between the patient and provider.

The literature describes the importance of appropriate communication in adherence; and how without it, misunderstanding and misuse of medication often occur. ${ }^{32,33}$ Pharmacists often assume that physicians explain the importance of the medications they prescribe, and assume that physicians routinely inquire about their patients' problems with therapies. This is often not the case. ${ }^{32}$ Health care education should emphasize the importance of physicians proactively facilitating discussions with their patients to prevent non-adherence issues before they occur. ${ }^{5}$

Communication is not the only factor that affects adherence. Many patients find it difficult and/or embarrassing when asked to discuss reasons for missing doses or other inappropriate drug use. These difficulties are lessened when the patient has a supportive, trusting relationship with their health care provider. ${ }^{31}$ Thompson described how having an empathetic, respectful provider who is a good listener improves patients' adherence to therapy. ${ }^{33}$

A patient's individual characteristics, health beliefs, situational factors, disease states and therapies, as well as a provider's relationship with their patient and communication skills are all predictors of medication adherence. While this evidence is strong, there is little evidence that explores whether discordance exists between health care providers' beliefs regarding reasons for medication nonadherence and the problems that patients actually experience when taking medications.

Results from our study indicated that both patients and students were in agreement regarding the top three reasons for medication non-adherence-lending credence to student perceptions on these factors. However, when the 16 factors were grouped into categories, the data revealed that students were more likely to believe that cognitive-related issues such as confusion, complexity, and lack of general understanding about their medications were of high significance in their patients' ability to adhere to a prescribed regimen. This was in contrast to what patients self-reported, which focused on factors related to lifestyle, including the high cost of medications, inability to drink alcohol with medication, and the negative impact medications have on their sexual health.

The very strong correlations between the two years of patient data, and between the two years of student data, demonstrated reliability of patient experiences, as well as student perceptions over time. Two independent groups of patients reported similar adherence issues with consistency in both years. Therefore, health care providers should facilitate discussions with their patients on these common concerns to assist in curtailing non-adherence. Likewise, pharmacy education should include discussions with students on common misconceptions highlighted in this research, and potential reasons for the discordance, such as generational differences, stereotyping, and assumptions. Hincapie described the opportunities that exist for health care professionals to "raise awareness about medication adherence." ${ }^{4}$ Understanding our own perceptions and biases, and the influential factors contributing to non-adherence provides a foundation for purposeful educational instruction. Didactic curricula, laboratory simulations, and experiential education are all viable avenues to ensure that training translates into clinical expertise.

This study has limitations. When reviewing relevant literature in preparation for this student assignment, the instructor noted that each article presented its own set of limitations, making it difficult to assess the strength of evidence for specific predictors of medication nonadherence. Therefore, many common factors are likely to be missing from the list. Additionally, the data used in this study was derived from a student assignment designed for student learning - not for research purposes. The data collected from the interview assignment with patients differed from the student perceptions data in that they were collected through use of different scales (ratings and rankings). Therefore, the rating scale data was converted to rankings for comparison. Also, the patient and student data were derived from different years in the curriculum, which prohibited the researchers from comparing the perceptions of a particular student with his/her individual patient.

Additional research would enhance the information gained through this study. Examples include: collecting student perceptions both before and after working with patients who exhibit medication non-adherence, asking students to reflect on their rationale following their rankings of reasons for non-adherence and qualitatively analyzing their thought processes, and evaluating students' effectiveness with motivating patients to take their 


\section{American Journal of Pharmaceutical Education 2018; 82 (9) Article 6444.}

medications. Additionally, providing students opportunities to work with multiple non-adherent patients over time coupled with guided discussions throughout their experiences would help prevent students from generalizing their perceptions based on one patient's situation.

\section{CONCLUSION}

This research study identified discordance between patient and student perspectives regarding some common factors leading to medication non-adherence. Without recognizing that perceptions may differ, health care providers may not be able to discern and address the true reasons for their patients' non-adherence to therapy. Inclusion of this information in health care curricula provides opportunities for deeper student learning, enhanced empathy for patients, and increased motivation to improve patient health. ${ }^{18,34-37}$ This, in turn, improves professional competence, enhances communication skills, and builds patients' trust. These are essential elements in explaining the reason(s) for non-adherence to prescribed therapy and individualizing an approach or tool to improve adherence. ${ }^{33,38-42}$ The authors presented a model that demonstrates how inclusion of these research findings within pharmacy education could lead to improved patient outcomes. The model also provides examples of educational opportunities for inclusion in a pharmacy curriculum. This new knowledge can be applied to medication adherence curricula at other pharmacy colleges, and in other health care disciplines.

\section{ACKNOWLEDGMENTS}

This research was presented as a student poster presentation at the 2016 American Society of Health-System Pharmacists Midyear Clinical Meeting and Exhibition.

\section{REFERENCES}

1. World Health Organization. Adherence to long-term therapies: evidence for action. 2003. http://www.who.int/chp/knowledge/ publications/adherence_introduction.pdf?ua=1. Accessed June 21, 2016. 2. Cramer JA, Roy A, Burrell A, et al. Medication compliance and persistence: terminology and definitions. Value Health. 2008;11(1):44-47. 3. Osterberg L, Blaschke T. Adherence to medication. $N$ Engl J Med. 2005;353(5):487-497.

4. Hincapie AL, Taylor AM, Boesen KP, Warholak T. Understanding reasons for nonadherence to medications in a Medicare Part D beneficiary sample. J Manag Care Spec Pharm. 2015;21(5):391-399.

5. Svensson S, Kjellgren KI, Ahlner J, Säljö R. Reasons for adherence with antihypertensive medication. Int J Cardiol. 2000;76(2-3):157-163.

6. Caro JJ, Salas M, Speckman JL, Raggio G, Jackson JD.

Persistence with treatment for hypertension in actual practice. CMAJ. 1999;160:31-37.

7. Pasina L, Brucato AL, Falcone C, et al. Medication non-adherence among elderly patients newly discharged and receiving polypharmacy. Drugs Aging. 2014;31(4):283-289.
8. Claxton AJ, Cramer J, Pierce C. A systematic review of the associations between dose regimens and medication compliance. Clin Ther. 2001;23(8):1296-1310.

9. McHorney CA, Spain CV. Frequency of and reasons for medication non-fulfillment and non-persistence among American adults with chronic disease in 2008. Health Expect. 2010;14:307-320. 10. Slejko JF, Ho M, Anderson HD, Nair KV, Sullivan PW, Campbell JD. Adherence to statins in primary prevention: yearly adherence changes and outcomes. J Manag Care Pharm. 2014;20(1):51-57. 11. Cramer J, Rosenheck R, Kirk G, Krol W, Krystal J; VA Naltrexone Study Group 425. Medication compliance feedback and monitoring in a clinical trial: predictors and outcomes. Value Health. 2003;6(5):566-573.

12. Haynes RB, McDonald HP, Garg AX. Helping patients follow prescribed treatment: clinical applications. JAMA. 2002;288(22): 2880-2883.

13. Sokol MC, McGuigan KA, Verbrugge RR, Epstein RS. Impact of medication adherence on hospitalization risk and healthcare cost. Med Care. 2005;43(6):521-530.

14. Andrade SE, Kahler KH, Frech F, Chan KA. Methods for evaluation of medication adherence and persistence using automated databases. Pharmacoepidemiol Drug Saf. 2006;15(8):565-574. 15. Vermeire E, Hearnshaw H, Van Royen P, Denekens J. Patient adherence to treatment: three decades of research. A comprehensive review. J Clin Pharm Ther. 2001;26(5):331-342.

16. Weidenbacher HJ, Beadles CA, Maciejewski ML, Reeve BB, Voils CI. Extent and reasons for nonadherence to antihypertensive, cholesterol, and diabetes medications: the association with depressive symptom burden in a sample of American veterans. Patient Prefer Adherence. 2015;9:327-336.

17. Rickles NM, MacLean LG, Hess K, et al. Teaching medication adherence in US colleges and schools of pharmacy. Am J Pharm Educ. 2012;76(5):Article 79.

18. Darbishire PL, Plake KS, Kiersma ME, White JK. An introductory pharmacy practice experience on improving medication adherence. Am J Pharm Educ. 2012;76(3):Article 42.

19. Divine HS, Cain J. Assessing the effect of a polypharmacy medication adherence simulation project in a geriatrics course in a college of pharmacy. J Am Geriatr Soc. 2009;57(8):1487-1491. 20. Ulbrich T, Hamer D, Lehotsky K. Second-year pharmacy students' perceptions of adhering to a complex simulated medication regimen. Am J Pharm Educ. 2012;76(1):Article 11.

21. Volino LR, Das RP, Mansukhani RP, Cosler LE. Evaluating the potential impact of pharmacist counseling on medication adherence using a simulation activity. Am J Pharm Educ. 2014;78(9):Article 169. 22. Svarstad BL, Chewing BA, Sleath BL, Claesson C. The brief medication questionnaire: a tool for screening patient adherence and barriers to adherence. Patient Educ Couns. 1999;37(2):113-124. 23. Morisky DE, Ang A, Krousel-Wood M, Ward HJ. Predictive validity of a medication adherence measure in an outpatient setting. $J$ Clin Hypertens. 2008;10(5):348-354.

24. Fialko L, Garety PA, Kuipers E, et al. A large-scale validation study of the Medication Adherence Rating Scale (MARS). Schizophr Res. 2008;100(1-3):53-59.

25. Risser J, Jacobson TA, Kripalani S. Development and psychometric evaluation of the Self-efficacy for Appropriate Medication Use Scale (SEAMS) in low-literacy patients with chronic disease. J Nurs Meas. 2007;15(3):203-219.

26. Hahn SR, Park J, Skinner EP, et al. Development of the ASK-20 Adherence Barrier Survey. Curr Med Res Opin. 2008;24(7):21272138 . 


\section{American Journal of Pharmaceutical Education 2018; 82 (9) Article 6444.}

27. Kim MT, Hill MN, Bone LR, Levine DM. Development and testing of the Hill-Bone Compliance to High Blood Pressure Therapy Scale. Prog Cardiovasc Nurs. 2000;15(3):90-96.

28. Mathes T, Jaschinski T, Pieper D. Adherence influencing factors - a systematic review of systematic reviews. Arch Public Health. 2014;72:37. 29. Mukhtar O, Weinman J, Jackson SH. Intentional non-adherence to medications by older adults. Drugs Aging. 2014;31(3):149-157. 30. Mert DG, Turgut NH, Kelleci M, Semiz M. Perspectives on reasons of medication nonadherence in psychiatric patients. Patient Prefer Adherence. 2015;(9):87-93.

31. Walsh JC, Horne R, Dalton M, Burgess AP, Gazzard BG. Reasons for non-adherence to antiretroviral therapy: patients' perspectives provide evidence of multiple causes. AIDS Care. 2001;13(6):709-720.

32. Tarn DM, Heritage J, Paterniti DA, Hays RD, Kravitz RL, Wenger NS. Physician communication when prescribing new medications. Arch Intern Med. 2006;166(17):1855-1862.

33. Thompson L, McCabe R. The effect of clinician-patient alliance and communication on treatment adherence in mental health care: a systemic review. BMC Psychiatry. 2012;12:87.

34. Chen JT, LaLopa J, Dang DK. Impact of patient empathy modeling on pharmacy students caring for the underserved. Am J Pharm Educ. 2008;72(2):Article 40.
35. Evans S, Lombardo M, Belgeri M, Fontane P. The Geriatric Medication Game in pharmacy education. Am J Pharm Educ. 2005;69(3): Article 46.

36. Wilkes M, Milgrom E, Hoffman JR. Towards more empathic medical students: a medical student hospitalization experience. Med Educ. 2002;36(6):528-533.

37. Kwekkeboom KL. The placebo effect in symptom management. Oncol Nurs Forum. 1997;24(8):1393-1399.

38. Street RL, Makoul G, Arora NK, Epstein RM. How does communication heal? Pathways linking clinician-patient communication to health outcomes. Patient Educ Couns. 2009; 74(3):295-301.

39. Arora NK. Interacting with cancer patients: the significance of physicians' communication behavior. Soc Sci Med. 2003;57(5):791806.

40. Stewart M, Brown JB, Donner A, et al. The impact of patientcentered care on outcomes. J Fam Pract. 2000;49(9):796-804.

41. Stewart MA. Effective physician-patient communication and health outcomes: a review. Can Med Assoc J. 1995;152(9):14231433.

42. Kaplan SH, Greenfield S, Ware Jr JE. Assessing the effects of physician-patient interactions on the outcomes of chronic disease. Med Care. 1989;27(3 Suppl):S110-S127. 